\title{
Late Retinal Progenitor Cells Show Intrinsic Limitations in the Production of Cell Types and the Kinetics of Opsin Synthesis
}

\author{
Michael J. Belliveau, Tracy L. Young, and Constance L. Cepko \\ Department of Genetics, and Howard Hughes Medical Institute, Harvard Medical School, Boston, Massachusetts 02115
}

The seven major cell classes of the vertebrate neural retina arise from a pool of multipotent progenitor cells. Several studies suggest a model of retinal development in which both the environment and the progenitor cells themselves change over time (Cepko et al., 1996). To test this model, we used a reaggregate culture system in which a labeled population of progenitor cells from the postnatal rat retina were cultured with an excess of embryonic retinal cells. The labeled cells were then assayed for their cell fate choices and their kinetics of rod differentiation, as measured by opsin synthesis. The kinetics of opsin synthesis remained unchanged, but fewer postnatal cells adopted the rod cell fate when cultured with embryonic cells. There was an

The vertebrate CNS is composed of a multitude of cell types. How these cells are generated during development is a central problem in neurobiology. A model system for the study of cell fate decisions has been the neural retina. The seven major retinal cell types arise from a pool of multipotent progenitor cells (Turner and Cepko, 1987; Holt et al., 1988; Wetts and Fraser, 1988). Retinal cell types are generated in a particular order; e.g., in rodents certain cell types are produced in the embryonic period, and others are produced in the early postnatal period (for review, see Altshuler et al., 1993). Because a degree of multipotency has been shown to persist throughout retinal development, it has been proposed that cell fate choices are influenced by extrinsic factors (Turner et al., 1990; Reh, 1991). However, it has been unclear how much of the information regarding cell fate decisions is intrinsic to progenitor cells and how much influence the environment can exert in terms of cell types produced by progenitor cells. Similarly, it has been unclear whether progenitor cells from different ages are equivalent or different regarding their ability to make the different cell types.

We showed previously that embryonic progenitor cells, when cultured in the presence of excess postnatal retinal cells, could be altered in their cell fate decisions (Belliveau and Cepko, 1999). There was a significant decrease in the percentage of amacrine cells born from embryonic day 16 (E16) progenitor cells, as well as an increase in the percentage of cone photoreceptors. Because rod photoreceptors are the major cell type produced postnatally, it was surprising to find that there was no increase in the percent-

\footnotetext{
Received Sept. 30, 1999; revised Nov. 23, 1999; accepted Dec. 29, 1999.

We are grateful to Drs. J. Hurley, J. Nathans, R. Molday, N. Onada, and J. Saari for gifts of primary antibodies and to Ann Vernallis and John Heath for the antagonist hLIF-05. This work was supported by National Institutes of Health Grant EY08064 (C.L.C.) and a National Science Foundation predoctoral fellowship (T.Y.).

Correspondence should be addressed to Dr. Constance L. Cepko, Department of Genetics and Howard Hughes Medical Institute, Harvard Medical School, 200 Longwood Avenue, Boston, MA 02115. E-mail: cepko@rascal.med.harvard.edu. Copyright (C) 2000 Society for Neuroscience $0270-6474 / 00 / 202247-08 \$ 15.00 / 0$
}

increase in the percentage of bipolar cells produced by postnatal progenitor cells, indicating a possible respecification of fate. The increase in bipolar cells could occur even after progenitor cells had completed their terminal mitoses. These alterations in cell fates appeared to be caused at least in part by a secreted factor released by the embryonic cells that requires the LIFR//gp130 complex for signaling. Finally, although surrounded by 20 -fold more embryonic cells, the postnatal cells did not choose to adopt any fates normally produced only by embryonic cells.

Key words: progenitor cell; opsin; retina; bipolar cell; rod photoreceptor; embryonic retinal cell; rhodopsin kinetics age of cells adopting the rod cell fate. Moreover, the E16 cells did not adopt cell fates restricted to postnatal ages, namely the bipolar cell and Müller glial cell fate. Thus it appears that although extrinsic cues can alter the fate of the cell types produced by embryonic progenitor cells, they are limited by the intrinsic repertoire of the progenitor pool, (Belliveau and Cepko, 1999; Cepko, 1999).

In this study, we further analyzed the ability of progenitor cells to respond to extrinsic cues by culturing reaggregates in which postnatal day $0(\mathrm{P} 0)$ cells were surrounded by an excess of E16 cells. The primary postmitotic fate of $\mathrm{P} 0$ progenitor cells is the rod photoreceptor fate (Alexiades and Cepko, 1997; Ezzeddine et al., 1997; M. M. LaVail, personal communication). Previous work had established that diff usible molecules could influence rod development in vitro. For example, secreted factors have been shown to inhibit (Lillien, 1995; Kirsch et al., 1996; Ezzeddine et al., 1997; Neophytou et al., 1997; Kirsch et al., 1998) or stimulate (Altshuler et al., 1993; Kelley et al., 1994; Levine et al., 1997) rod development when added to rodent retinal cultures. Perhaps the best evidence that a retinal factor or factors may be required for rod development is from culture experiments in which $\mathrm{P} 0$ retinal cells were placed at various cell densities. As the cells became more sparse, they no longer adopted the rod cell fate, and at least some adopted an alternative fate, that of bipolar cells (Altshuler and Cepko, 1992). Interestingly, application of CNTF or related cytokines produced a similar effect on P0 retinae cultured as organ explants (Ezzeddine et al., 1997). These data together suggest a possible "tug of war" between the signals that direct two fates: those of rods and bipolar cells.

A second aspect of rod development examined in the current study was the regulation of the kinetics of rhodopsin expression. We showed previously that embryonic rod precursor cells display a variable lag between their terminal mitosis and expression of rhodopsin (Morrow et al., 1998). In contrast, cells undergoing their terminal mitosis on or after E19 displayed a fixed lag of $\sim 6$ 
d to rhodopsin expression. When cultured, embryonic progenitor cells born before E19 displayed the same long and variable lags seen in vivo. Surprisingly, embryonic progenitor cells, when cultured in the presence of excess postnatal retinal cells, did not change either their kinetics for rhodopsin expression or the percentage of cells adopting the rod fate (Morrow et al., 1998). These data suggest that there are intrinsic limitations within embryonic progenitor cells regarding rod development.

To examine which properties of $\mathrm{P} 0$ progenitor cells are intrinsic, we performed mixing experiments in which $\mathrm{P} 0$ retinal progenitor cells were labeled with a short pulse of $\left[{ }^{3} \mathrm{H}\right]$ thymidine, reaggregated with 20 -fold more E16 retinal cells, and cultured for $>2$ weeks. The fate choices of the immediate progeny of the labeled P0 progenitor cells were then assayed with cell typespecific antibodies. As was observed when E16 cells were examined in the presence of excess P0 cells, the kinetics of rhodopsin expression by the P0 cells was not altered, suggesting again that the kinetics are intrinsically controlled. However, in contrast to what we observed when E16 cells were surrounded by P0 cells, in the current study, the production of rods by $\mathrm{P} 0$ cells was dramatically altered by surrounding them with an excess of E16 cells. Fivefold fewer P0 cells adopted the rod cell fate. The P0 cells previously fated to become rods instead expressed markers for the bipolar cell fate. There was also a small increase in the production of amacrine cells. However, there was no production of cells that normally are generated embryonically but not postnatally, such as cone photoreceptors. The ability of the P0-born cells to be altered in their cell fate choice was maintained after the cells had undergone their terminal mitosis. Finally, we found evidence that embryonic cells secrete a rod-inhibiting factor or factors. The factor(s) requires signaling through the LIFR $\beta$ / gp130 complex that serves as a receptor for CNTF, leukemia inhibitory factor (LIF), and other members of their cytokine family. These data, together with previous reaggregate culture experiments (Belliveau and Cepko, 1999), support the hypothesis that progenitor cells pass through phases of competence that dictate their response to extrinsic cues such that they produce particular repertoires of cell types (Cepko et al., 1996). Once the cells have passed through a phase, they cannot be induced to return to it. This is distinct in some aspects from the observations made for cerebral cortical progenitor cells, as will be discussed.

\section{MATERIALS AND METHODS}

Animals. Timed pregnant Sprague Dawley rats were purchased from Taconic Laboratories (Germantown, NY).

$\left[{ }^{3} H\right]$ thymidine labeling. For all culture experiments, the mitotic P0 cells were pulse-labeled with $\left[{ }^{3} \mathrm{H}\right]$ thymidine. Retinae were dissected free of surrounding tissues and placed into DF10 [45\% DME, 45\% Ham's F12 Nutrient Mixture (Life Technologies, Gaithersburg, MD), 10\% FCS and penicillin/streptomycin $(100 \mathrm{U} / \mathrm{ml})]$ containing $5 \mu \mathrm{Ci}\left[{ }^{3} \mathrm{H}\right]$ thymidine $/ \mathrm{ml}$ for $1 \mathrm{hr}$ at $37^{\circ} \mathrm{C}$. Retinae were subsequently rinsed by three media changes. Labeled cells were cultured as described below. Retinae were then dissociated as described previously (Altshuler and Cepko, 1992). The interval from the end of the $\left[{ }^{3} \mathrm{H}\right]$ thymidine labeling to the beginning of the culture was $30-40 \mathrm{~min}$.

Reaggregate cultures. The reaggregate pellet culture protocol was performed as described previously (Belliveau and Cepko, 1999). $\left[{ }^{3} \mathrm{H}\right]$ thymidine-labeled P0 retinae were dissociated as described above for the dissociation of fresh retinal tissue. Cells were counted and pelleted in a microcentrifuge tube containing 20 -fold excess, unlabeled E16 retinal cells by centrifugation for $7 \mathrm{~min}$ at $1150 \times g$. The total per pellet was $5 \times 10^{5}$ to $1 \times 10^{6}$ cells. Pellets were transferred to nucleopore polycarbonate membranes, $0.2 \mu \mathrm{m}$ pore size (Costar, Cambridge, MA), and cultured for $3,5,7,10,12,15$, or $17 \mathrm{~d}$ as described previously in DF10. At the end of the culture period, pellets were dislodged from the membranes, dissociated, and processed autoradiographically and immunocytochemically as described below.

Gel cultures. P0 retinae, previously labeled with $\left[{ }^{3} \mathrm{H}\right]$ thymidine, and E16 retinae were dissociated as described above for the dissociation of fresh retinal tissue into single cells. Cells were cast into a collagen gel matrix, and cocultures of two gels were set up as described previously (Altshuler and Cepko, 1992). P0 cells in the center well were plated at high density $\left(8 \times 10^{5} \mathrm{P} 0\right.$ cells $\left./ 40 \mu \mathrm{l}\right)$, and for controls with a gel of P0 cells surrounding the central gel, the surrounding P0 cells were cast at $4 \times 10^{6} \mathrm{P} 0$ cells $/ 200 \mu \mathrm{l}$. For experiments in which the center gel of P0 cells was cocultivated with E16 cells, the P0 cells in the central gel were $8 \times 10^{5} \mathrm{P} 0$ cells $/ 40 \mu \mathrm{l}$, and the surrounding E16 cells were $4 \times 10^{6} \mathrm{E} 16$ cells $/ 200 \mu$ l. All gels were cultured in defined medium (Bottenstein and Sato, 1979). Gel cultures incubated with the LIFR $\beta$ antagonist hLIF-05 (Hudson et al., 1996) included $5 \mu \mathrm{g} / \mathrm{ml}$ of the antagonist. Gel cultures were maintained for $10 \mathrm{~d}$. Cells were then dissociated and processed autoradiographically and immunocytochemically as described below. Autoradiography was performed to ensure that the P0 cells from the central well were the population scored for marker expression.

Dissociation of cultures. Pellets were dissociated by sinking the filters into the well medium to detach the cells, transferring the pellets to $\mathrm{Ca}^{2+}$ and $\mathrm{Mg}^{2+}$-free HBSS, and then processing them as described above for the dissociation of fresh retinal tissue into single cells. Gels were dissociated as described previously (Altshuler et al., 1993). Once dissociated, the cells were plated on coated eight-well glass slides (Cel-Line Associates) coated with $100 \mu \mathrm{l}$ of $10 \mu \mathrm{g} / \mathrm{ml}$ poly-D-lysine for $20 \mathrm{~min}$. The cells were allowed to attach at $37^{\circ} \mathrm{C}$ for $1-2 \mathrm{hr}$, then fixed in $4 \%$ formaldehyde for 10-20 min. The slides were then processed for immunocytochemistry.

Immunocytochemistry. Slides were blocked for $1 \mathrm{hr}$ in $2 \%$ donkey serum, $2 \%$ goat serum, and $0.1 \%$ Triton X-100 detergent in PBS. Primary antibody incubation for $1 \mathrm{hr}$ used blocking solution containing primary antibody [VC1.1 (1:1000, Sigma, St. Louis, MO), anti-mGluR2/3 (1:300, Chemicon, Temecula, CA), recoverin (1:1000) (Dizhoor et al., 1991), cone opsins (1:10,000) (Wang et al., 1992; Chiu and Nathans, 1994), 115A10 (neat) (Onodo and Fujita, 1987), anti-calbindin (1:300, Sigma), and anti-CR ALBP (1:10,000) (De Leeuw et al., 1990). Anti-rhodopsin staining with Rho4D2 (1:250) (Molday, 1989) was performed as described previously (Ezzeddine and Cepko, 1997). Anti-BrdU staining was performed per the direction of the supplier (Amersham, Arlington Heights, IL). Previous studies detected no mGluR3 RNA or protein in the rat retina (Hartveit et al., 1995; Koulen et al., 1996). Hence, the antibody was most likely detecting mGluR2 protein. Specificity of antibody labeling was verified by immunohistochemistry (data not shown).

Incubation in primary antibody was followed by three PBS rinses and 20 min in blocking solution containing Texas Red-conjugated donkey anti-mouse or donkey anti-rabbit secondary antibodies (1:200, Jackson ImmunoResearch, West Grove, PA). Nuclear staining was performed by adding 4',6-diamidine-2-phenylindole-dihydrochloride (DAPI) to the wash solution at a final concentration of $0.0005 \%$. Slides were then processed for autoradiography.

Autoradiography. Cells becoming postmitotic the day of $\left[{ }^{3} \mathrm{H}\right]$ thymidine pulse administration were identified as described previously (Young, 1985). Slides with $\left[{ }^{3} \mathrm{H}\right]$ thymidine-labeled cells were dipped in NTB2 autoradiography emulsion (Eastman Kodak, Rochester, NY). Slides were exposed for $5 \mathrm{~d}$ at $4^{\circ} \mathrm{C}$ in the dark. Slides were then developed for 5 min in D19 developer (Kodak), rinsed in distilled water, and then fixed for $20 \mathrm{~min}$ in fixer (Kodak). Slides were washed with distilled water for $10 \mathrm{~min}$, then mounted in gelvatol. Slides were examined using a Zeiss Axiophot using a $63 \times$ Plan NEOFLUAR objective.

The relative quantity of $\left[{ }^{3} \mathrm{H}\right]$ thymidine per cell was estimated based on the number of silver grains, visualized by light microscopy, inside and around the cell nucleus. Cells displaying at least $n / 2$ grains (where $n=$ the number of silver grains in the most heavily labeled cell) were estimated to be "heavily labeled" and to have been born on P0 (Morrow et al., 1998). The identity later assumed by these cells was assessed by scoring individual heavily labeled cells for expression of various cell type markers.

\section{RESULTS}

To study the relative roles of extrinsic and intrinsic regulation of cell fate choices, we used a reaggregate culture protocol that allowed for the mixing of test cells with a host population, culturing for $>2$ weeks to allow for differentiation, and subsequent identification of individual cells from the test population 
born on a particular day to assess that cell's fate choice. Reaggregate cultures from embryonic and postnatal rat retinae have been shown to generate rod photoreceptors with kinetics similar to those in vivo (Watanabe and Raff, 1990; Morrow et al., 1998). Furthermore, interneurons, cone photoreceptors, and Müller glia have also been shown to be generated in this culture system (Watanabe et al., 1997; Belliveau and Cepko, 1999).

\section{Necessity of the postnatal environment for the rod cell} fate choice but not for regulation of rhodopsin kinetics

The importance of secreted factors in determining how many postnatal cells differentiate as rods has been shown in vitro by previous experiments in which $\mathrm{P} 0$ cells were placed into lowdensity collagen gel cultures (Altshuler and Cepko, 1992). In these experiments, fewer cells expressed rhodopsin after $7 \mathrm{~d}$ in culture, relative to cells in high density collagen gels or retinal explants in vitro. If, however, these cells were also provided with medium conditioned by postnatal retinae, the percentage of cells that expressed rhodopsin increased (Altshuler and Cepko, 1992). When birth-dated E16 cells cultured in the presence of excess postnatal retinal cells were assayed for their expression of rhodopsin, it was observed that the E16-born cells appeared uninfluenced by the environmental signals created by an excess of P0 cells with respect to both the onset of rhodopsin expression and the percentage of such cells committing to the rod cell fate. These data supported the notion that the embryonic progenitor cells were intrinsically different from their postnatal counterparts and could not respond to any factors present in the postnatal environment (Morrow et al., 1998). These studies did not distinguish whether there was an inhibitor in the embryonic environment that, like the postnatal environment, might regulate either the kinetics or final expression of rhodopsin among E16-born cells. To examine this possibility, we mixed $\left[{ }^{3} \mathrm{H}\right]$ thymidine-labeled $\mathrm{P} 0$ retinal progenitor cells with a 20 -fold excess of E16 retinal cells and cultured them for 3-17 d (Fig. 1). After culturing, the reaggregates were dissociated and processed immunocytochemically and autoradiographically. Cells were assayed for the presence of silver grains and anti-rhodopsin labeling. Cells containing $>50 \%$ of the maximum grain count were regarded as having undergone their terminal mitosis immediately after labeling (Morrow et al., 1998) and were termed "birth-dated" or "heavily labeled." This subset was selected for analysis. The control reaggregates displayed properties of rhodopsin expression similar to those seen in vivo; birth-dated E16 cells displayed a lag of $>1$ week, whereas the birth-dated P0 cells first began to express rhodopsin by $3 \mathrm{~d}$ in vitro (DIV). Moreover, the final percentage of rhodopsin-expressing cells was approximately fivefold higher in P0 control reaggregates cultured in the absence of E16 cells than in E16 control reaggregates cultured in the absence of P0 cells (Fig. 1).

When $\left[{ }^{3} \mathrm{H}\right]$ thymidine-labeled $\mathrm{P} 0$ cells were reaggregated with an excess of unlabeled E16 cells, the percentage of birth-dated P0 cells expressing rhodopsin was greatly decreased relative to $\mathrm{P} 0$ reaggregate controls at all time points examined. As shown, $6.3 \pm$ $2.1 \%$ of cells initiating their terminal S-phase in P0 explants expressed rhodopsin after 5 DIV with excess E16 cells, versus $25.0 \pm 5.9 \%$ for such cells cultured with an excess of other P0 cells. After rod differentiation was completed in culture at 17 DIV, $16.0 \pm 2.0 \%$ of birth-dated P0 progenitor cells expressed rhodopsin when cultured with E16 cells versus $67.0 \pm 3.7 \%$ when cultured alone (Fig. 1). Although the values were lower, the kinetics of rhodopsin by birth-dated P0 cells appeared unaffected
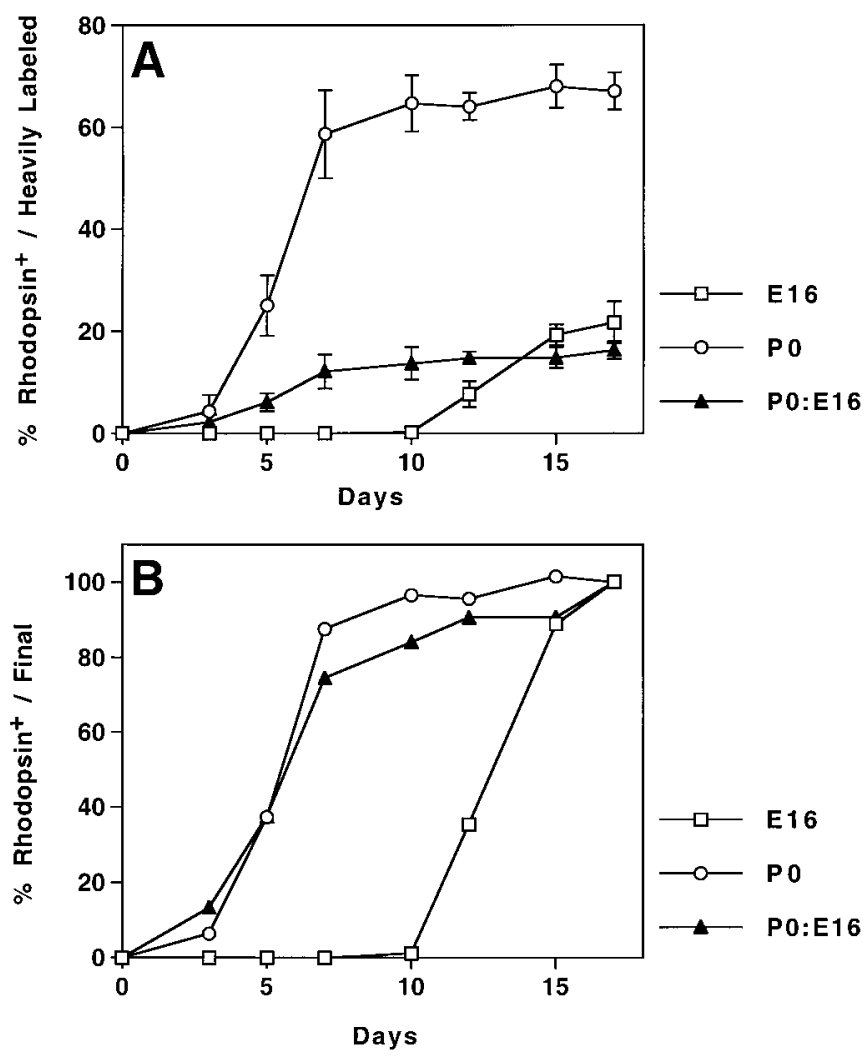

Figure 1. Requirement of the postnatal environment for the rod cell fate but not for the regulation of rhodopsin kinetics. Reaggregate cultures of E16 ( $\square)$, P0 (O), or P0-E16 (P0:E16, 1:20; $\mathbf{\Delta})$ were cultured for the indicated number of days. They were then dissociated and processed for immunocytochemistry and autoradiography. Birth-dated cells were scored for their labeling with anti-rhodopsin. Data are expressed as either the percentage of heavily labeled cells expressing rhodopsin $(A)$ or as a percentage of the cells expressing rhodopsin after 17 DIV $(B)$. Values represent the mean $\pm \mathrm{SD}$ of three to six trials. For each trial, $\geq 100$ heavily labeled cells were assayed.

by the embryonic neighbors. When cultured either with 20 -fold more E16 cells or when cultured alone, the first birth-dated, rhodopsin-positive P0 cells were detected after 3 DIV, and the plateau of rhodopsin expression was reached by 7 DIV. In contrast, the first birth-dated, rhodopsin-positive E16 cells were detected after 10 DIV, and the plateau was reached by 15 DIV.

\section{Cells fated to become rod photoreceptors adopt the bipolar cell fate when cultured in the embryonic environment}

What was the fate of the P0 cells that would normally have become rods? Two strong possibilities were that the cells were becoming either the predominant fates of embryonically born cells, such as horizontal cells and/or cone photoreceptors, or that they were adopting an alternative postnatal cell fate, such as bipolar cells. Another possible fate was that of the amacrine cell, which is produced both embryonically and postnatally in the rat (Alexiades and Cepko, 1997; M. M. LaVail, personal communication). We showed previously that the postnatal environment contained an activity that inhibited the genesis of amacrine cells from E16 progenitor cells (Belliveau and Cepko, 1999). This activity, which appears to be produced by postmitotic amacrines themselves, could also be serving to regulate the production of amacrine cells from the P0 progenitor cells. Moreover, the E16 host age is near the peak of amacrine cell production (Alexiades 


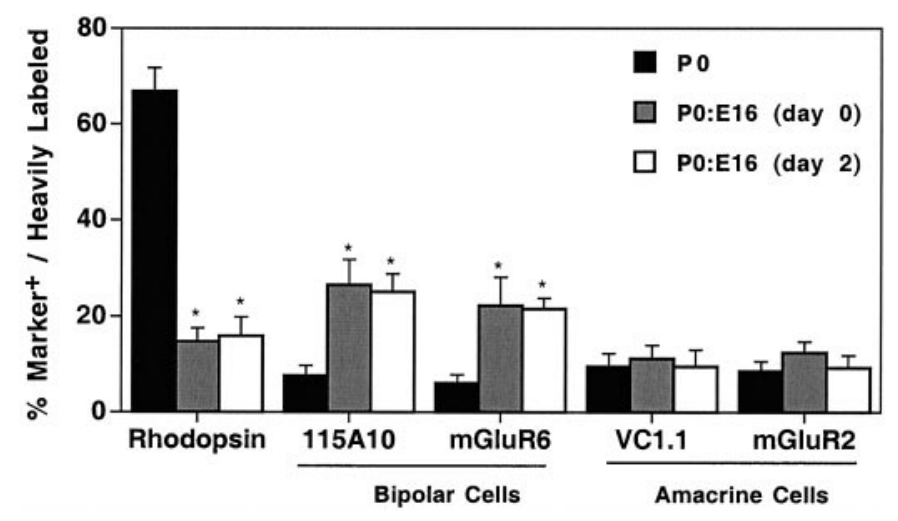

Figure 2. Alteration of the fate of postmitotic cells produced by postnatal progenitor cells when cultured with excess embryonic cells. Reaggregate cultures were maintained for $15 \mathrm{DIV}$, then dissociated and processed immunocytochemically and autoradiographically. Birth-dated cells were scored for labeling with the indicated antibodies. When P0 cells were cultured alone (black bars), nearly $70 \%$ of the birth-dated cells became rods. This value was reduced fivefold when $\left[{ }^{3} \mathrm{H}\right]$ thymidine-labeled $\mathrm{P} 0$ progenitor cells were reaggregated with 20 -fold more E16 retinal cells on day 0 (gray bars) or day 2 (white bars). Values represent the mean \pm SD of three to six trials. For each trial, $\geq 100$ heavily labeled cells were assayed. ${ }^{*} p<0.01$.

and Cepko, 1997; M. M. LaVail, personal communication). Thus, in the mixed culture, the P0 progenitor cells would be moved out of an amacrine-inhibiting environment and placed in one that supports the production of amacrine cells. Bipolar cells, like amacrine cells, are normal progeny of $\mathrm{P} 0$ progenitor cells. When $\mathrm{P} 0$ progenitor cells are placed in low-density collagen gels, or alternatively cultured as retinal explants in the presence of CNTF, there is both a decrease in rods and an increase in bipolar cells (Altshuler and Cepko, 1992; Ezzeddine et al., 1997). To determine whether there was an increase in the production of either amacrine or bipolar cells, labeled P0 retinal progenitor cells were mixed with a 20-fold excess of E16 retinal cells and cultured for $15 \mathrm{~d}$. After culturing, the reaggregates were dissociated, processed immunocytochemically and autoradiographically, and scored for the bipolar and amacrine cell fates, as defined by labeling with either 115A10 and mGluR6, for the bipolar cell fate, or VC1.1 and mGluR2, for the amacrine cell fate.

When P0 cells were cultured with a 20-fold excess of E16 cells, there was an increase in the production of bipolar cells. In the control reaggregates, $7.6 \pm 2.2 \%$ and $6.0 \pm 1.8 \%$ of the heavily labeled P0 cells were $115 \mathrm{~A} 10$ positive and mGluR6 positive after 15 DIV (Fig. 2). In contrast, $26.5 \pm 5.2 \%$ and $22.1 \pm 6.0 \%$ of the birth-dated $\mathrm{P} 0$ cells were $115 \mathrm{~A} 10$ positive and mGluR6 positive, respectively, when these cells were cultured with 20 -fold more E16 cells (Fig. 2). There was no significant increase in the production of amacrine cells. In the control reaggregates, $9.5 \pm 2.7 \%$ and $8.6 \pm 2.0 \%$ of the heavily labeled $\mathrm{P} 0$ cells were VC1.1 positive and mGluR2 positive, respectively, after 15 DIV (Fig. 2). In contrast, $11.1 \pm 2.8 \%$ and $12.4 \pm 2.2 \%$ of the birth-dated P0 cells were VC1.1 positive and mGluR2 positive, respectively, when these cells were cultured with 20 -fold more E16 cells (Fig. 2). Similarly, there was no increase in the production of the fourth major cell type generated postnatally: the Müller glial cell (Table 1).

As mentioned above, another possibility was that when the postnatal progenitor cells were exposed to an embryonic environment, they would be induced to adopt the normal fates of embry-
Table 1. Quantification of antigen expression by heavily labeled cells after 15 DIV

\begin{tabular}{llrcc} 
& \multicolumn{4}{c}{ Reaggregate type } \\
\cline { 3 - 5 } Cell type & Antibody & \multicolumn{1}{c}{ E16 } & \multicolumn{1}{c}{ P0 } & \multicolumn{1}{c}{ P0-E16 } \\
\hline Amacrine & mGluR2 & $25.7 \pm 2.3$ & $8.6 \pm 2.0$ & $12.4 \pm 2.2$ \\
Horizontal & Calbindin & $6.5 \pm 1.4$ & $0.0^{a}$ & $0.0^{a}$ \\
Cone & Cone opsins & $25.3 \pm 3.8$ & $0.0^{a}$ & $0.2 \pm 0.3$ \\
Rod & Rhodopsin & $20.0 \pm 1.7$ & $66.9 \pm 4.9$ & $14.7 \pm 2.8$ \\
Bipolar & 115A10 & $0.4 \pm 0.8$ & $7.6 \pm 2.2$ & $26.5 \pm 5.2$ \\
Müller & CRALBP & $0.0^{a}$ & $3.3 \pm 1.3$ & $4.2 \pm 1.4$ \\
Unidentified & & 22.1 & 13.6 & 42.0
\end{tabular}

$\overline{\text { Reaggregate cultures of E16, P0, or P0-E16 (1:20) were dissociated after } 15 \text { DIV. }}$ After they were processed for immunocytochemistry and autoradiography, birthdated cells were scored for their labeling by the indicated antibodies. Values represent the mean $\pm \mathrm{SD}$ of three to six trials. For each trial, $\geq 100$ heavily labeled cells were assayed.

${ }^{a}$ Zero out of 300 heavily labeled cells were marker-positive.

onically born cells. Two embryonically born cell types shown to be produced in embryonic reaggregate cultures are horizontal cells and cone photoreceptors (Belliveau and Cepko, 1999). When labeled P0 cells were cultured with 20-fold more unlabeled E16 cells for 15 DIV, there was no production of either of these cell types (Table 1), although they were produced in control E16 reaggregate cultures cultured similarly (Table 1 ).

\section{Alteration of fate can occur after terminal mitosis}

It was shown previously that cells fated to become rod photoreceptors could be respecified to the bipolar cell fate with the addition of CNTF (Ezzeddine et al., 1997). This respecification could occur even after the terminal mitosis of the progenitor cell. Thus, postmitotic cells born in the postnatal period displayed a degree of plasticity in their cell fate choice. In contrast, the inhibition of the E16-born cells from the amacrine cell fate by the postnatal environment had to occur before the terminal $\mathrm{M}$ phase of the E16 cell. After this time, the E16 cells were refractory to the influence of the postnatal environment (Belliveau and Cepko, 1999). To determine whether the E16 environment was capable of respecifying postmitotic cells born on $\mathrm{P} 0$, the following experiment was performed. P0 retinal explants were labeled with $\left[{ }^{3} \mathrm{H}\right]$ thymidine as described previously. These explants were cultured for $2 \mathrm{~d}$, then dissociated and reaggregated with 20-fold more E16 cells. The delay between $\left[{ }^{3} \mathrm{H}\right]$ thymidine labeling and the subsequent dissociation and reaggregation should be sufficient for all cells born on $\mathrm{P} 0$ to complete their final $\mathrm{M}$ phase (Alexiades and Cepko, 1996). Reaggregates were then maintained for 13 DIV, so that the total length of culture of $\mathrm{P} 0$ retinae was $15 \mathrm{~d}$. At this time, the reaggregates were dissociated and processed for immunocytochemistry and autoradiography.

The decrease in the percentage in rod photoreceptors and the increase in the percentage in bipolar cells when P0 cells were transferred to the reaggregate on day 2 were nearly identical to when they were transferred on day 0 (Fig. 2). These data suggest that, similar to the application of CNTF, transfer to the E16 environment led to the respecification of at least a subset of postmitotic cells fated to become rods.

\section{Reduction in production of rod photoreceptors is caused in part by inhibitory signals produced by embryonic retinal cells}

It has been shown previously that the postnatal retina produces a factor or factors that are required for the differentiation of rod 


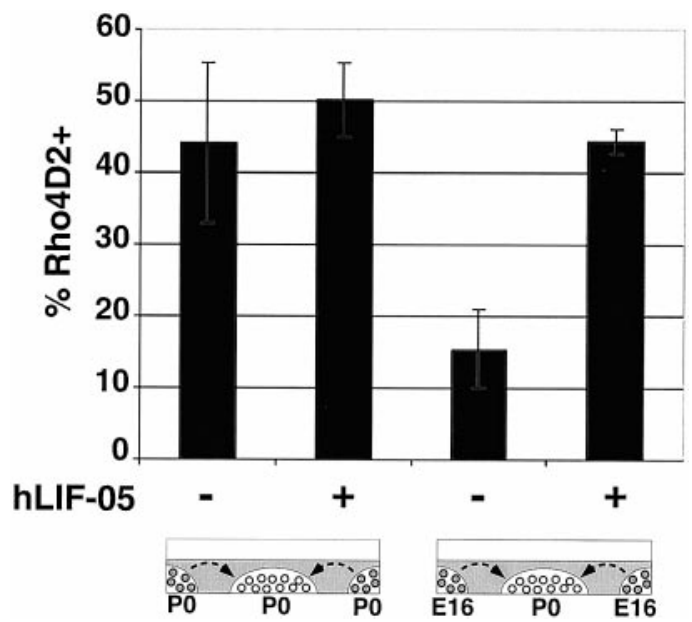

Figure 3. An inhibitor of rod production is produced by E16 cells, and it signals through a LIFR $\beta /$ gp 130 complex. P0 retinae were dissociated and cast at a density of $8 \times 10^{5}$ cells $/ 40 \mathrm{ml}$ collagen gel. These gels were placed in the center of a culture well in a defined medium with or without the LIFR $\beta$ antagonist hLIF-05 $(5 \mu \mathrm{g} / \mathrm{ml})$. The gels were cultured in the presence of a surrounding collagen gel containing E16 or P0 cells at $4 \times$ $10^{6}$ cells/200 $\mathrm{ml}$ for $10 \mathrm{DIV}$. No contact between cells in the two gels was detected. The cells were then removed from the center gel of P0 cells and processed for immunocytochemistry, and the percentage of rhodopsinpositive cells was determined. Values represent the mean \pm SD of three trials. For each trial, $>300$ cells were scored.

photoreceptors. The importance of such factors for the ability of postnatal cells to differentiate into rods is exemplified by previous experiments in which $\mathrm{P} 0$ cells were placed into low-density collagen gel cultures (Altshuler and Cepko, 1992). In these experiments, fewer cells expressed rhodopsin after 7 DIV. If, however, these cells were also provided with medium conditioned with postnatal retinae, the percentage of cells expressing rhodopsin increased (Altshuler and Cepko, 1992). Thus, in the experiments described here, when the P0 cells were cultured in the embryonic environment, it could be that the rod-promoting activity was absent. Alternatively, factors that inhibit rod differentiation in vitro have also been isolated (Lillien, 1995; Kirsch et al., 1996; Ezzeddine et al., 1997; Neophytou et al., 1997; Kirsch et al., 1998). These factors could be present in the embryonic tissue and inhibit rod cell development. To determine whether the embryonic cells were releasing a soluble inhibitor that could inhibit a P0 culture that had an environment that produced a sufficient amount of positively acting cues to support high-level rod production, we made cocultures of collagen gels. A high density of P0 cells placed in a collagen gel matrix were cultured in either the presence or absence of E16 cells. E16 cells were placed in an adjacent collagen gel that ringed the central gel containing the P0 cells (Fig. 3). After $10 \mathrm{DIV}$, the cells originating from the P0 retinae in the central gel were examined for their expression of rhodopsin. The embryonic cells appeared to be secreting an inhibitory activity (Fig. 3). Of the $\mathrm{P} 0$ retinal cells cultured in the absence of neighboring E16 cells, $44.2 \pm 11.2 \%$ were rhodopsin positive. This value decreased approximately threefold to $15.4 \pm$ $5.5 \%$ when $\mathrm{P} 0$ cells were cultured in the presence of neighboring E16 cells. These data suggested that E16 cells secrete a factor or factors that inhibit the adoption of the rod cell fate. A less likely, but possible, interpretation is that the E16 cells somehow caused a depletion in the rod-inducing activity made by P0 cells.

To test whether the inhibitor produced by E16 cells was a member of the CNTF family of cytokines, an inhibitor of signaling in this pathway was included in the gel cocultures. The antagonist hLIF-05 binds to LIFR $\beta$ but has lost affinity for gp130 (Hudson et al., 1996). Oligomerization and subsequent signaling through these receptors is thus lost. Antagonism of CNTF, LIF, oncostatin-M, and cardiotrophin-1 by hLIF-05 has been demonstrated, and thus this antagonist can relieve inhibition produced by any known member of this family of cytokines (Vernallis et al., 1997). Initially, we tested whether hLIF-05 could block signaling in the rat because antagonism in this species had not been established. We found that it could block the rod-inhibiting activity of exogenous CNTF added to a rat explant culture (S. E. St. Pierre and C. L. Cepko, unpublished data). The antagonist was thus added to control P0 gel cultures and to cocultures of P0 and E16 cells. The percentage of rhodopsin-positive cells among the $\mathrm{P} 0$ cells cultured in the presence of E16 cells and hLIF-05 was $44.4 \% \pm 1.7 \%$, which is indistinguishable from the control levels of $44.2 \pm 11.2 \%$ when $\mathrm{P} 0$ cells were cultured in the absence of E16 cells. These data indicate that the E16 inhibitor requires signaling through the LIFR $\beta / \mathrm{gp} 130$ receptor. These data also eliminate the possibility that the decrement in rhodopsin-positive cells is caused by the depletion of $\mathrm{P} 0$-produced stimulators by neighboring E16 cells.

\section{DISCUSSION}

In this study we have continued our analysis of the potential of retinal progenitor cells. Two aspects of retinal development were examined: extrinsic regulation of cell fate choice and rhodopsin expression kinetics. We showed previously that embryonic rod precursors display a variable lag between their terminal mitosis and expression of rhodopsin (Morrow et al., 1998). Cells undergoing their terminal mitosis on or after E19 display a fixed lag of $\sim 6 \mathrm{~d}$ to rhodopsin expression. Embryonic progenitor cells born before E19 display longer and variable lags in vivo or when cultured in vitro. When cultured in the presence of excess postnatal retinal cells, these cells did not change either their kinetics for rhodopsin expression or the final percentage of cells that become rods (Morrow et al., 1998). One interpretation is that the embryonic cells are intrinsically programmed regarding the kinetics of rhodopsin expression and the percentage of progenitor cells that can make rods. Here, we performed the inverse experiment and assayed the fate choice and rhodopsin kinetics of P0 retinal progenitor cells when cultured with an excess of embryonic cells. As in previous reaggregates, there was no change in the kinetics of rhodopsin expression, again suggesting that rhodopsin kinetics are controlled intrinsically. This observation further supports the idea that $\mathrm{P} 0$ progenitor cells that give rise to rods are intrinsically different from the E16 progenitor cells that give rise to rods. In contrast to our previous study of reaggregates in which E16 cells were the target of the P0 environment, in the current study an effect of the E16 environment on rod production by $\mathrm{P} 0$ cells was observed. Many fewer P0-born cells adopted the rod fate. The reduction in rod photoreceptors was accompanied by an increase in bipolar cells. There was no significant alteration in the percentage of two other postnatally born cell types: amacrine cells and Müller glia. The respecification from the rod fate to the bipolar fate could occur even after the terminal mitosis of the progenitor cell. Moreover, experiments in which P0 cells and E16 cells were cocultured in a system that prevented cell-cell contact between the two populations provided evidence that the observed cell fate switch was caused in part by a factor or factors released by the embryonic cells. This factor requires signaling through the 
LIFR $\beta /$ gp130 receptor complex and thus is likely a member of the CNTF family of cytokines.

\section{Postmitotic cells fated to become rods can be respecified by coculturing with embryonic cells}

It has been shown previously that there are both positive and negative factors that are able to regulate the rat rod cell fate in vitro (Altshuler et al., 1993; Kelley et al., 1994; Lillien, 1995; Kirsch et al., 1996; Ezzeddine et al., 1997; Levine et al., 1997; Neophytou et al., 1997; Kirsch et al., 1998). To date, however, the role of these factors in the development of the retina remains to be elucidated. Nearly $70 \%$ of the cells born on P0 are fated to become rods. When these cells are cocultured with 20 -fold more E16 cells, this percentage drops almost fivefold. After examination of the percentage of each cell type in the rat retina, we found that only one, the bipolar cell, was increased in the culture described above. From these data, we conclude that cells fated to become rods were being respecified to the bipolar cell fate. Interestingly, such a respecification has been observed previously because of other manipulations. When P0 retinal cells were cultured in a collagen gel matrix at a low density, fewer rods and more bipolars were detected (Altshuler and Cepko, 1992). Similarly, P0 retinal explants cultured in the presence of CNTF had a decrease in the percentage of rods and an increased percentage of bipolar cells (Ezzeddine et al., 1997). Taken together, these data suggest that later in retinal development there might be a bipotential precursor cell that can adopt either the rod or the bipolar cell fate and that this choice is regulated by extrinsic cues.

When could the P0 cells be respecified? In cultures in which E16 retinal cells were cocultured with 20 -fold more P0 cells, the embryonic cells could be respecified from the amacrine cell fate to the cone photoreceptor fate, but only if they were in the new environment before their terminal $\mathrm{M}$ phase (Belliveau and Cepko, 1999). Similar findings were reported for cortical progenitor cells making laminar fate decisions (McConnell and Kaznowski, 1991). On transplantation into the ventricular zone of older animals, early progenitor cells produced cells respecified to later fates (McConnell, 1988). This respecification required that the progenitor cells underwent mitosis within the new environment (McConnell and Kaznowski, 1991). Here, if the P0 cells were reaggregated with the excess E16 cells after their terminal $\mathrm{M}$ phase, they could still be respecified from the rod cell to the bipolar cell fate. Similarly, P0 cells could be respecified from the rod cell to the bipolar cell fate with the addition of CNTF, even after the P0-born cells had completed their terminal $\mathrm{M}$ phase (Ezzeddine et al., 1997). It is interesting that not all retinal cell fates are being fixed at the same time in the cell cycle.

\section{Reduction in production of rod photoreceptors is caused in part by inhibitory signals produced by embryonic retinal cells}

It has previously been shown that the postnatal retina produces a factor or factors that are required for the differentiation of rod photoreceptors. The importance of such factors for the ability of postnatal cells to differentiate into rods is exemplified by previous experiments in which $\mathrm{P} 0$ cells were placed into low-density collagen gel cultures (Altshuler and Cepko, 1992). In these experiments, fewer cells expressed rhodopsin after 7 DIV. If, however, these cells were also provided with factors produced by postnatal retinae, the percentage of cells expressing rhodopsin increased (Altshuler and Cepko, 1992). Thus, in the experiments described here, when the P0 cells were cultured in the embryonic environment, it could be that the rod-promoting activity was absent.
Alternatively, or additionally, factors that inhibit rod differentiation could have been present; factors added to retinal cultures have been shown to inhibit rod development (Lillien, 1995; Kirsch et al., 1996; Ezzeddine et al., 1997; Neophytou et al., 1997; Kirsch et al., 1998). However, rod inhibitory factors had not been shown to be present in embryonic tissue. To determine whether the embryonic cells were releasing a soluble inhibitor while also providing an environment that produced a sufficient amount of positively acting cues to support high level rod production, we made cocultures of collagen gels. A high density of P0 cells placed in a collagen gel matrix were cultured in either the presence or absence of E16 cells. The E16 cells were placed in an adjacent collagen gel that ringed the gel containing the P0 cells (Fig. 3). As a control for overall cell density, the control culture had P0 cells ringed by a collagen gel with P0 cells. After 10 DIV, the cells originating from the central gel of $\mathrm{P} 0$ cells were examined for their expression of rhodopsin. The embryonic cells appeared to be secreting an inhibitory activity, in that threefold fewer cells adopted the rod fate in the coculture of P0 and E16 cells (Fig. 3).

To determine whether the inhibitory activity provided by E16 cells was caused by a member of the CNTF cytokine family, an antagonist of this family was included in the P0-E16 gel cocultures. The antagonist hLIF-05 was developed by Hudson et al. (1996) and was shown by Vernallis et al. (1997) to block signaling through LIFR $\beta$ and gp130. All known ligands that signal through this receptor have been shown to suffer from antagonism by hLIF-05. Inclusion of hLIH-05 in the coculture of E16 and P0 cells completely relieved the inhibition of opsin-positive cells by E16 cells (Fig. 3). These data indicate that the drop in rod production in the coculture of $\mathrm{P} 0$ cells with E16 cells is caused at least in part by the production of a factor of the CNTF family of cytokines by E16 cells.

\section{Failure of the embryonic environment to alter rhodopsin expression kinetics of postnatal rods}

The kinetics of rhodopsin expression appear to be intrinsically programmed. Previously, we described the relationship between a cell's terminal mitosis and when it expressed rhodopsin (Morrow et al., 1998). For the vast majority of rods, those born on or after E19, there was a fixed lag of $\sim 6 \mathrm{~d}$ between exit from the cell cycle and onset of rhodopsin expression. Cells born before E19, however, exhibited a variable lag and approximately simultaneous expression of rhodopsin. Thus the earliest born rods wait the longest time before expressing rhodopsin. These data were consistent with a possible extrinsic regulation of rhodopsin expression, attributable to the presence of an inhibitor in the early retina, or the requirement of a factor in the later retina. When E16 retinal cells were mixed with 20 -fold more P0 cells, they maintained their long delay from their terminal mitosis to the onset of rhodopsin expression, although the neighboring cells were beginning to express rhodopsin. The long delay displayed by the embryonic cells appeared, then, to be intrinsically programmed. It was still possible, however, that the postnatal environment might contain an activity required for the $6 \mathrm{~d}$ kinetics of rhodopsin expression exhibited by P0 cells. To examine this, a careful time course of rhodopsin expression was determined for experimental and control reaggregate cultures. Although fewer P0-born cells expressed rhodopsin, the time course of rhodopsin expression remained unaffected by the surrounding embryonic cells. Thus the kinetics of rhodopsin expression appears to be intrinsically programmed. The mechanisms that regulate rhodopsin kinetics are currently unknown but appear to be able to keep 
$\begin{array}{llllllllllll}\text { E16 } & E_{17} & E_{1} 18 & E_{1} & E_{2} 0 & E_{1} 1 & E_{22} & P_{0} & P_{1} & P_{2} & P_{3} & P_{4}\end{array}$

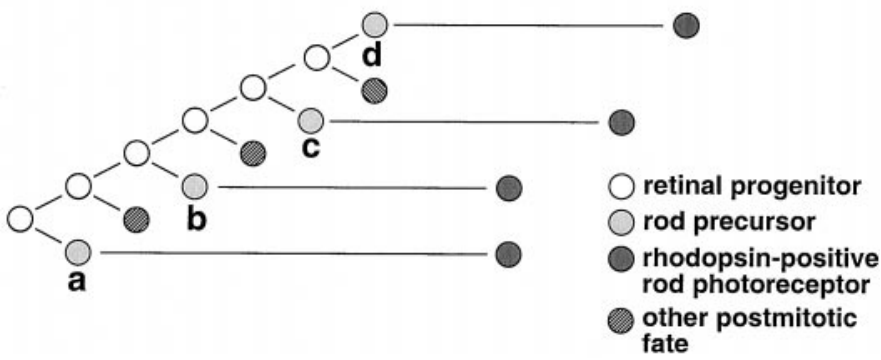

Figure 4. A model for regulation of the kinetics of rhodopsin expression. Retinal progenitor cells (white) divide to produce a combination of mitotic and postmitotic progeny. Cells fated to become rod cells (rod precursors; light gray) are postmitotic. After a delay, the cells begin to express rhodopsin and form outer segments (dark gray). For cells born before E19 $(A, B)$, the onset of rhodopsin appears synchronous. Thus, early-born rod precursors wait longer than later-born rod precursors before expressing rhodopsin. For cells born on or after E19 $(C)$, there is a fixed lag of, on average, $\sim 6 \mathrm{~d}$, although the first rhodopsin-positive cells appear 48-72 hr after the terminal mitosis. The regulation of rhodopsin expression can be thought of as having two phases. The first phase lasts up to E19 in the rat and appears to involve a mechanism of counting that does not depend on cell division and is capable of keeping a postmitotic cell $(A)$ and a mitotic cell $(B)$ in synchrony. The second phase lasts $\sim 6 \mathrm{~d}$ and begins either on E19 (for the early cells) or after the cell has undergone its terminal mitosis. Heterochronic experiments suggest that the control of timing is cell intrinsic.

time. A similar intrinsic mechanism has been described for oligodendrocyte precursors in the rat optic nerve (Temple and Raff, 1986). In this example, accumulation of the cyclin-dependent kinase inhibitor $\mathrm{p} 27 \mathrm{Kip} 1$ is thought to regulate exit from the cell cycle and subsequent differentiation (Durand et al., 1997, 1998; Gao et al., 1997). Although it was initially believed that the intrinsic mechanism was counting cell divisions (Temple and Raff, 1986), it now appears that it measures time. The intrinsic mechanism regulating rhodopsin expression also appears to somehow measure time. Indeed, the counting described here appears to take place in both mitotic and postmitotic cells (Fig. 4). The purpose of the time delay between the terminal mitosis and the expression of rhodopsin is unclear. For a small population, this delay in the rat can be $>2$ weeks, and even for the vast majority, the lag is $\sim 6 \mathrm{~d}$ (Morrow et al., 1998). The increase in rhodopsin levels in the rod population coincides with the formation of rod outer segments. As photoreceptor outer segments form in the same location where the mitotic cells undergo $\mathrm{M}$ phase, perhaps rhodopsin expression and outer segment formation are coordinated and delayed until after cell production is nearly complete. This delay is seen in all species studied (for review, see Cepko, 1996).

\section{Early retinal environment does not recruit late progenitor cells to early cell fates}

Different cell types are being generated at different times during retinal development. Because there has been evidence that environmental signals can influence cell fate choices, it was possible that the early retinal environment would lead to the adoption of early fates by late progenitor cells. In fact, we found no early cell types produced by late progenitor cells placed in an early environment, suggesting that the cells have lost the competence and/or potential to adopt the early cell fates. This is in agreement with previous reaggregate experiments, in which early progenitor cells did not adopt fates of late progenitor cells (Belliveau and
Cepko, 1999), and further supports a model in which retinal progenitor cells pass through phases of competence at which time they have the capacity to adopt a particular fate or fates. Through some unknown mechanism, the progenitor cell moves out of that phase and into a new one. This progression appears to be unidirectional. Thus, once a cell has passed through a phase, it cannot return to it.

Another possible explanation of our observations is that there was differential survival or proliferation between the experimental and control culture conditions. We find this possibility highly unlikely for the following reasons. If the decrease in the percentage of rods when P0 cells were cocultured with 20-fold more E16 cells was the result of selective rod cell death, then one would expect that the proportion of all of the other cell types produced by $\mathrm{P} 0$ cells would increase. This would be caused simply by a change in the total number of P0-born cells because rods are such a significant fraction of P0-born cells. We did not observe this. Rather, the percentage of two other cell types, amacrine cells and Müller glia, remained unchanged between the two conditions. Thus, amacrine cells and Müller glia, but not bipolar cells, would also have to die in the same proportions as rods to produce the observed result. We found no evidence to support this possibility. Similarly, a proliferative event that would lead to a decrease in rods and an increase in bipolar cells and no change in the other two cell types would require increased production of bipolar cells, and, to a lesser extent, of amacrine cells and Müller glia. Finally, the combination of differential proliferation and survival, although possible, seems to be quite unlikely, because it would need to be perfectly balanced to give the observed results.

\section{Comparison with other regions of the nervous system}

The above data suggest that retinal progenitor cells of different ages have distinct intrinsic biases toward particular cell fates and that these biases are temporally regulated. Intrinsic differences among chick retinal progenitor cells of different ages placed in culture have also been observed (Austin et al., 1995). Although nearly $70 \%$ of E4 progenitor cells maintained in low-density collagen gel culture adopted the ganglion cell fate, only $5 \%$ of E7 progenitor cells did so when cultured similarly. Moreover, when late chick progenitor cells were transplanted into early developing retina, they did not adopt early fates, but rather remained restricted to later ones (Fekete et al., 1990). Similarly, later cortical progenitor cells transplanted into early ferret ventricular zone did not adopt the early fates but adopted laminar fates appropriate for their age (Frantz and McConnell, 1996). In contrast, however, late-migrating chick neural crest cells substituted for an earlymigrating population behaved like early migrating crest (Baker et al., 1997), suggesting that neural crest cells do not become progressively restricted. In contrast, Raible and Eisen (1996) showed that late-migrating zebrafish crest cells did not form neurons, either during normal development or when transplanted into an early environment. These cells could form neurons, however, if the early-migrating cells were ablated, suggesting that the earlymigrating cells inhibit the late-migrating cells from adopting the neuronal fate (Raible and Eisen, 1996).

It appears that during retinal development, changes in both the progenitor cells and the retinal environment serve to regulate the production of cell types in the proper ratio and order. Few of the molecules involved in this coordination have been identified. In particular, early progenitor cells must be expressing a different set of genes from later progenitor cells. It appears that at least those progenitor cells biased to produce amacrine and horizontal cells 
can be identified by their precocious expression of two markers of mature amacrine and horizontal cells (Alexiades and Cepko, 1997), whereas early chick retinal progenitor cells precociously express a marker of the earliest born cell type, ganglion cells (Austin et al., 1995). However, the presumed upstream genes that regulate expression of such markers in subsets of progenitor cells have not been identified. The advent of techniques that allow a comprehensive description of the genes expressed by individual cells make this area of study ripe for investigation.

\section{REFERENCES}

Alexiades MR, Cepko C (1996) Quantitative analysis of proliferation and cell cycle length during development of the rat retina. Dev Dyn 205:293-307.

Alexiades MR, Cepko CL (1997) Subsets of retinal progenitor cells display temporally regulated and distinct biases in the fates of their progeny. Development 124:1119-1131.

Altshuler D, Cepko C (1992) A temporally regulated, diffusible activity is required for rod photoreceptor development in vitro. Development 114:947-957.

Altshuler D, LoTurco JJR, Rush J, Cepko CL (1993) Taurine promotes the differentiation of a vertebrate retinal cell type in vitro. Development 119:1317-1328.

Austin CP, Feldman DE, Ida JA, Cepko CL (1995) Vertebrate retinal ganglion cells are selected from competent progenitor cells by the action of Notch. Development 121:3637-3650.

Baker CV, Bronner-Fraser M, Le Douarin NM, Teillet MA (1997) Early- and late-migrating cranial neural crest cell populations have equivalent developmental potential in vivo. Development 124:30773087.

Belliveau MJ, Cepko CL (1999) Entrinsic and intrinsic factors control the genesis of amacrine and cone cells in the rat retina. Development 126:555-566

Bottenstein JE, Sato GH (1979) Growth of a rat neuroblastoma line in serum-free supplemented medium. Proc Natl Acad Sci USA 76:514-517.

Cepko CL (1996) The patterning and onset of opsin expression in vertebrate retinae. Curr Opin Neurobiol 6:542-546.

Cepko CL (1999) The roles of intrinsic and extrinsic cues and bHLH genes in the determination of retinal cell fates. Curr Opin Neurobiol 9:37-46.

Cepko CL, Austin CP, Yang X, Alexiades M, Ezzeddine D (1996) Cell fate determination in the vertebrate retina. Proc Natl Acad Sci USA 93:589-595.

Chiu MI, Nathans J (1994) A sequence upstream of the mouse blue visual pigment gene directs blue cone-specific transgene expression in mouse retinas. Vis Neurosci 11:773-780.

De Leeuw AM, Gaur VP, Saari JC, Milam AH (1990) Immunolocalization of cellular retinol-, retinaldehyde- and retinoic acid-binding proteins in rat retina during pre- and postnatal development. J Neurocytol $2: 253-264$

Dizhoor AM, Ray S, Kumar S, Niemi G, Spencer M, Brolley D, Walsh KA, Philipov PP, Hurley JB, Stryer L (1991) Recoverin: a calcium sensitive activator of retinal rod guanylate cyclase. Science 251:915-918.

Durand B, Gao F-B, Raff M (1997) Accumulation of the cyclindependent kinase inhibitor p27/Kip1 and the timing of oligodendrocyte differentiation. EMBO J 16:306-317.

Durand B, Fero ML, Roberts JM, Raff MC (1998) p27Kip1 alters the response of cells to mitogen and is part of a cell-intrinsic timer that arrests the cell cycle and initiates differentiation. Curr Biol 8:431-440.

Ezzeddine ZD, Yang X, DeChiara T, Yancopoulos G, Cepko CL (1997) Postmitotic cells fated to become rod photoreceptors can be respecified by CNTF treatment of the retina. Development 124:1055-1067.

Fekete DM, Ryder EF, Stoker AW, Cepko CL (1990) Neuronal lineage and determination in the chick retina using retroviruses and cell transplants. Neurosci Abstr 16:1272.

Frantz GD, McConnell SK (1996) Restriction of late cerebral cortical progenitor cells to an upper-layer fate. Neuron 17:55-61.

Gao F-B, Durand B, Raff M (1997) Oligodendrocyte precursor cells count time but not cell divisions before differentiation. Curr Biol $7: 152-155$
Hartveit E, Brandstatter JH, Enz R, Wässle H (1995) Expression of the mRNA of seven metabotropic glutamate receptors (mGluR1 to 7) in the rat retina. An in situ hybridization study on tissue sections and isolated cells. Eur J Neurosci 7:1472-1483.

Holt CE, Bertsch TW, Ellis HM, Harris WA (1988) Cellular determination in the Xenopus retina is independent of lineage and birth date. Neuron 1:15-26.

Hudson KR, Vernallis AB, Heath JK (1996) Characterization of the receptor binding sites of human leukemia inhibitory factor and the creation of antagonists. J Biol Chem 271:11971-11978.

Kelley MW, Turner JK, Reh TA (1994) Retinoic acid promotes differentiation of photoreceptors in vitro. Development 120:2091-2102.

Kirsch M, Fuhrmann S, Wiese A, Hofmann H-D (1996) CNTF exerts opposite effects on in vitro development of rat and chick photoreceptors. NeuroReport 7:697-700.

Kirsch M, Schulz-Key S, Wiese A, Fuhrmann S, Hofmann H-D (1998) Ciliary neurotrophic factor blocks rod photoreceptor differentiation from postmitotic precursor cells in vitro. Cell Tissue Res 291:207-216.

Koulen P, Malitschek B, Kuhn R, Wässle H, Brandstatter JH (1996) Group II and group III metabotropic glutamate receptors in the rat retina: distributions and developmental expression patterns. Eur J Neurosci 8:2177-2187.

Levine EM, Roelink H, Turner J, Reh TA (1997) Sonic hedgehog promotes rod photoreceptor differentiation in mammalian retinal cells in vitro. J Neurosci 17:6277-6288.

Lillien L (1995) Changes in retinal cell fate induced by overexpression of EGF receptor. Nature 377:158-162.

McConnell SK (1988) Fates of visual cortical neurons in the ferret after isochronic and heterochronic transplantation. J Neurosci 8:945-974.

McConnell SK, Kaznowski CE (1991) Cell cycle dependence of laminar determination in developing neocortex. Science 252:282-285.

Molday RS (1989) Monoclonal antibodies to rhodopsin and other proteins of rod outer segments. Prog Ret Res 8:173-209.

Morrow EM, Belliveau MJ, Cepko CL (1998) Two phases of rod photoreceptor differentiation during rat retinal development. J Neurosci 18:3738-3748.

Neophytou C, Vernallis AB, Smith A, Raff MC (1997) Müller-cellderived leukemia inhibitory factor arrests rod photoreceptor differentiation at a postmitotic pre-rod stage of development. Development 124:2345-2354

Onodo N, Fujita SC (1987) A monoclonal antibody specific for a subpopulation of retinal bipolar cells in the frog and other vertebrates. Brain Res 416:359-363.

Raible DW, Eisen JS (1996) Regulative interactions in zebrafish neural crest. Development 122:501-507.

Reh TA (1991) Determination of cell fate during retinal histogenesis: intrinsic and extrinsic mechanisms. In: Development of the visual system (Lam DM-K, Shatz CJ, eds), pp 79-94. Cambridge, MA: M IT.

Temple S, Raff MC (1986) Clonal analysis of oligodendrocyte development in culture: evidence for a developmental clock that counts cell divisions. Cell 44:773-779.

Turner DL, Cepko CL (1987) A common progenitor for neurons and glia persists in rat retina late in development. Nature 328:131-136.

Turner DL, Snyder EY, Cepko CL (1990) Lineage-independent determination of cell type in the embryonic mouse retina. Neuron 4:833-845.

Vernallis AB, Hudson KR, Heath JK (1997) An antagonist for the leukemia inhibitory factor receptor inhibits leukemia inhibitory factor, cardiotrophin-1, ciliary neurotrophic factor, and oncostatin M. J Biol Chem 272:26947-26952.

Wang Y, Macke JP, Merbs SL, Zack DJ, Klaunberg B, Bennett J, Gearhart J, Nathans J (1992) A locus control region adjacent to the human red and green visual pigment genes. Neuron 9:429-440.

Watanabe T, Raff MC (1990) Rod photoreceptor development in vitro: intrinsic properties of proliferating neuroepithelial cells change as development proceeds in the rat retina. Neuron 2:461-467.

Watanabe T, Voyvodic J, Chan-Ling T, Sagara H, Hirosawa K, Mio Y, Matsushima S, Uchimura H, Nakahara K, Raff MC (1997) Differentiation and morphogenesis in pellet cultures of developing rat retinal cells. J Comp Neurol 377:341-350.

Wetts R, Fraser SE (1988) Multipotent precursors can give rise to all major cell types of the frog retina. Science 239:1142-1145.

Young RW (1985) Cell differentiation in the retina of the mouse. Anat Rec 212:199-205. 